\title{
ANALISIS PENGEMBANGAN STRATEGI PEMASARAN HALAL PADA USAHA KECIL MENENGAH PRODUK WEDANG UWUH DAN TEPUNG BEBAS GLUTEN DI UKM PROGRESS JOGJA
}

\author{
Vembri Noor Helia \\ Jurusan Teknik Industri, Fakultas Teknologi Industri, Universitas Islam Indonesia \\ Jl.Kaliurang Km.14,5, Sleman, Yogyakarta, 55584 \\ E-Mail : heliaaqilah@gmail.com
}

\begin{abstract}
The government is encouraging small businesses to improve product quality by adjusting its product in accordance with the Standar Nasional Indonesia (SNI-Indonesian National Standardization). Halal is one aspect of quality, especially in the food and beverage products, which is considered in Indonesia, due to most of Indonesian is Moslem. This research was aimed to develop halal marketing strategies for specific SME (Small Medium Enterprise) that produced "wedang uwuh" beverage and gluten-free flour in Yogyakarta. The SME is called SMEs Progress Jogja. The marketing strategy in SMEs Progress Jogja was developed using a questionnaire that distributed to stakeholders. The tools which for analysis were SWOT matrix and QSPM. There are three expected strategies by the SMEs Progress Jogja that should be selected. The strategies were expanding the market share (especially by exploiting the defense of government), developing/increasing product variation, and also preserving the quality and the halal requirement of products. Then, the chosen strategy that was selected by using the priority matrix QSP is to expand market share.
\end{abstract}

Keywords : Halal Marketing Strategies, Wedang Uwuh, SMEs, SWOT.

\section{PENDAHULUAN}

Pemerintah mendorong usaha kecil meningkatkan kualitas produk dengan menyesuaikan produknya sesuai dengan Standar Nasional Indonesia, sehingga diharapkan dapat membantu produk UKM dalam negeri agar dapat bersaing dengan barang-barang impor yang masuk sesuai dengan berlakunya MEA. Kawasan ASEAN akan terbentuk menjadi pasar terbuka yang berbasis produksi, dimana aliran barang, jasa, dan investasi akan bergerak bebas sesuai dengan kesepakatan ASEAN, sehingga persaingan ketat bukan lagi secara domestik atau lokal dalam satu negara, tapi sudah regional di Asia Tenggara. Produk UKM selain harus memiliki Standar Nasional Indonesia, diharapkan juga memiliki sertifikat halal dari MUI (Majelis Ulama Indonesia). Halal menjadi syarat yang mutlak bagi umat Islam, dimana mayoritas masyarakat Indonesia beragama Islam dengan jumlah presentase sebesar $85 \%$ (Putra, 2016).
Dengan jumlah penduduk mencapai 241 juta, Indonesia berpotensi sebagai basis ekonomi atau konsumsi terbesar di kawasan ASEAN (Suhaimi, 2016). Hal itu, dapat dipandang bahwa MEA sebagai ancaman. Di sisi lain, bagi UKM yang siap menghadapi liberalisasi perdagangan akan menjadi peluang untuk memasarkan produknya atau jasa mereka ke negara lain. Salah satu UKM yang mulai berkembang dan bahkan sudah go international ke beberapa negara adalah UKM Progress Jogja sebagai penghasil produk wedang uwuh dengan kemasan yang cukup menarik. Berada di provinsi Daerah Istimewa Yogyakarta, UKM produk wedang uwuh mulai dikenal masyarakat. Bahkan, wedang uwuh telah menjadi ikon Kabupaten Bantul, Provinsi DIY. Dinas Perindustrian Perdagangan dan Koperasi Kabupaten Bantul, Daerah Istimewa Yogyakarta berupaya menjadikan minuman khas tradisional dari daerah ini "wedang uwuh" agar mampu bersaing dengan minuman modern (Republika, 2014). 
Pada UKM Progress Jogja, pemasaran masih dilakukan secara spontan tanpa adanya perencanaan. Hal ini berkaitan dengan ketersediaan dana yang terbatas dan lebih dipergunakan untuk kepentingan produksi terlebih dahulu, sehingga harus mampu menciptakan sistem pemasaran yang efektif dan efisien.

Manfaat perancangan strategi pemasaran pada UD Suryani Furniture menurut penelitian dari Ningrum (2010) adalah dapat menentukan prioritas yang tepat dalam pengembangan usaha analisis internal dan eksternal, yaitu menetapkan strategi harga dan pasar untuk menghadapi persaingan. Konsep pemasaran yang dikembangkan di atas adalah menggunakan teori pemasaran dari Kotler maka kemudian pada konsep pemasaran halal dikembangkan dengan menambahkan aspek kepatuhan terhadap syariat Islam untuk pembentukan nilai bagi konsumen. Belum banyak dilakukan penelitian mengenai pemasaran halal, sehingga peneliti merasa perlu untuk menambahkan konsep halal dalam pemasaran berdasarkan konsep yang dikembangkan oleh Salehudin \& Mukhlis (2012).

Tidak hanya dari Indonesia, konsep pemasaran halal juga telah dikembangkan di India sebagai negara dengan penduduk muslim terbesar ketiga setelah Indonesia dan Pakistan. Ditunjukkan disini bahwa pemasaran halal tidak hanya untuk produk makanan dan bank, tetapi juga dikembangkan pada produk farmasi, kosmetik, fashion, pendidikan, hiburan, dan jasa tourism (Islam \& Candrasekaran, 2013).

Untuk menjawab berbagai tantangan dalam persoalan penerapan pemasaran yang efektif dan efisien sekaligus halal di UKM, maka penting untuk dikaji bagaimana pengembangan strategi pemasaran halal untuk UKM yang spesifik sesuai dengan kebutuhan UKM produk wedang uwuh serta merujuk kepada model pemasaran halal yang ada. Belum pernah ada penelitian sebelumnya terhadap pengembangan pemasaran halal di UKM produk wedang uwuh, sehingga penelitian ini dapat menjadi acuan untuk pembuatan strategi pemasaran halal di UKM.

\section{LANDASAN TEORI \\ 2.1. Definisi UMKM}

Menurut RUU UMKM, usaha kecil yaitu usaha milik WNI dengan jumlah karyawan 6-19 orang kecuali sektor jasa dan perdagangan, kekayaan bersih Rp 50-500 juta dan / atau penjualan tahunan Rp 300-2,5 miliar dan berdiri sendiri. Sedangkan berdasarkan definisi Departemen koperasi dan UMKM, usaha kecil adalah kegiatan ekonomi yang dilakukan oleh perseorangan atau rumah tangga maupun suatu badan yang bertujuan untuk memproduksi barang atau jasa untuk diperniagakan secara komersial dan mempunyai omzet penjualan sebesar satu miliar rupiah atau kurang.

\subsection{Manajemen Strategi}

David (2004) mendefinisikan manajemen strategis merupakan ilmu tentang perumusan dan evaluasi keputusan keputusan lintas fungsi yang memungkinkan organisasi mencapai tujuannya. Menajemen strategis terfokus pada upaya memadukan menajemen pemasaran, keuangan / akuntansi, peoduksi penelitian dan pengembangan, dan sistem informasi untuk mencapai keberhasilan dalam organisasi.

\subsection{Tahapan Penyusunan Strategi}

Lingkungan bisnis dapat dibagi menjadi dua, yaitu lingkungan eksternal dan lingkungan internal. Lingkungan eksternal merupakan suatu proses yang dilakukan oleh perencanaan strategi untuk memantau sektor lingkungan dalam menentukan peluang dan ancaman bagi perusahaan.

Kekuatan eksternal dapat dibagi menjadi dua yaitu lingkungan makro dan lingkungan industri. Menurut David (2004) mengelompokkan lingkungan umum meliputi lima segmen yang terdiri atas faktor ekonomi, sosial budaya, politik dan kebijakan pemerintah, teknologi serta demografi. Sedangkan aspek lingkungan industri akan lebih mengarah pada aspek persaingan dimana perusahaan berada. 


\begin{tabular}{|c|c|c|}
\hline EFE & $\begin{array}{l}\text { STRENGTHS (S) } \\
\text { Tentukan } 5 \text { - } 10 \text { faktor - faktor } \\
\text { kekuatan internal }\end{array}$ & $\begin{array}{c}\text { WEAKNESSES }(\mathrm{W}) \\
\text { Tentukan } 5 \text { - } 10 \text { faktor - faktor } \\
\text { kelemahan internal }\end{array}$ \\
\hline $\begin{array}{l}\text { OPPORTUNITIES }(\mathrm{O}) \\
\text { Tentukan 5-10 faktor- } \\
\text { faktor peluang eksternal }\end{array}$ & $\begin{array}{c}\text { STRATEGI S-O } \\
\text { Ciptakan strategi menggunakan } \\
\text { kekuatan untuk memanfaatkan } \\
\text { peluang. } \\
\end{array}$ & $\begin{array}{c}\text { STRATEGI W-O } \\
\text { Ciptakan strategi } \\
\text { meminimalkan kelemahan } \\
\text { untuk memanfaatkan peluang.. }\end{array}$ \\
\hline $\begin{array}{l}\text { THREATHS }(\mathrm{T}) \\
\text { Tentukan 5-10 faktor- } \\
\text { faktor ancaman eksternal }\end{array}$ & $\begin{array}{c}\text { STRATEGI S-T } \\
\text { Ciptkaan strategi yang } \\
\text { menggunakan kekuatan untuk } \\
\text { mengatasi ancaman. }\end{array}$ & $\begin{array}{c}\text { STRATEGI W-T } \\
\text { Ciptakan strategi yang } \\
\text { meminimalkan kelemahan dan } \\
\text { menghindari ancaman. }\end{array}$ \\
\hline
\end{tabular}

Gambar 1. Analisis SWOT.

Faktor - faktor yang mempengaruhi kondisi persaingan, seperti ancaman pada perusahaan dan kekuatan yang dimiliki oleh perusahaan termasuk kondisi persaingan industri tersebut meliputi 5 kekuatan Porter, yaitu pendatang baru, produk pengganti, pembeli, pemasok dan pesaing.

Lingkungan internal merupakan suatu kondisi yang ada di dalam suatu perusahaan. Analisis internal adalah proses perencanaan strategi menentukan letak kekuatan dan kelemahan suatu perusahaan.

Lingkungan internal menurut David (2004) merupakan kekuatan dan kelemahan perusahaan pada area fungsional bisnis, termasuk manajemen, pemasaran, keuangan / akuntansi, produksi / operasi, penelitian dan pengembangan, dan sistem informasi manajemen.

\subsection{Formulasi Strategi}

Aplikasi untuk menentukan strategi utama berdasarkan konsep Fred R. David dilakukan melalui pemakaian beberapa matriks dengan tiga tahap pelaksanaan, yaitu tahap pengumpulan data input (The Input Stage), tahap pemanduan (The Matching Stage), dan tahap penetapan strategi (The Decision Stage). Pada analisis SWOT mempertimbangkan Strengths (kekuatan), Weaknesses (kelemahan), Opportunities (peluang) dan Threats (ancaman) dan strategi yang diterapkan tampak dalam gambar 1.

\subsection{Strategi Pemasaran Halal}

Pemasaran Halal atau Halal marketing merupakan pengembangan dari konsep pemasaran konvensional dengan menambahkan aspek kepatuhan terhadap syariat Islam (Syariah Compliance) dalam proses pembentukan nilai bagi konsumen (Saalehudin \& Mukhlis, 2012). Jika Philip Kotler (1999) mendefinisikan pemasaran sebagai proses sosial dimana individu dan kelompok mendapatkan apa yang mereka butuhkan dan inginkan melalui penciptaan, penawaran dan pertukaran barang dan jasa yang memiliki nilai tertentu dengan individu atau kelompok lain dengan bebas; maka dengan demikian pemasaran halal dapat didefinisikan sebagai proses sosial dimana individu dan kelompok mendapatkan apa yang mereka butuhkan dan inginkan melalui penciptaan, penawaran dan pertukaran barang dan jasa yang memiliki nilai tertentu dengan individu atau kelompok lain sesuai kaidah dan tuntunan yang ditetapkan oleh Syari'at Islam.

\section{METODE PENELITIAN}

\subsection{Metode Pengumpulan Data}

Metode pengumpulan data pada penelitian ini adalah dengan melakukan pengumpulan data primer dan data sekunder. Pengumpulan data primer dilakukan melalui penyebaran kuesioner dan wawancara kepada empat narasumber penelitian, yaitu pemilik, bagian keuangan, bagian produksi dan konsumen. Data - data yang di kumpulkan dalam wawancara adalah data 
mengenai identifikasi faktor - faktor strategis lingkungan eksternal, yaitu lingkungan makro, sosial, budaya, demografi, politik dan kebijakan pemerintah, teknologi, pesaing dan lingkungan internal meliputi sumber daya manusia, keuangan, produksi dan operasi, pemasaran, penelitian dan pengembangan. Kemudian, dibuat kuesioner untuk mendapatkan bobot dan rating dari hasil rangkuman identifikasi eksternal dan internal. Pengumpulan data sekunder diperoleh melalui telaah dokumen seperti peraturan perundangan mengenai definisi UKM, profil UKM, proses bisnis UKM, data penjualan dan data pesaing, serta studi literatur yang terkait dengan penelitian ini.

\subsection{Metode Pengolahan Data}

Terdapat tiga tahapan dalam proses perumusan alternatif strategi, yaitu tahap pengumpulan data (Input Stage), tahap analisis (matching stage), dan tahap pengambilan keputusan (decision stage). Pengolahan data internal dan eksernal dilakukan dengan menggunakan Microsoft Excel dan dilengkapi dengan uji validitas dan reliabilitas pada kuesioner yang diolah menggunakan program SPSS untuk mengetahui kelayakan butir - butir dalam suatu daftar (konstruk) pertanyaan dan mendefinisikan variabel.

Tahap pengumpulan data dibagi menjadi dua, yaitu data eksternal dan data internal. Data yang teridentiifikasi dalam pengamatan lapangan, dirangkum dalam suatu matriks, yaitu External Factor Evaluation (EFE) dan Internal Factor Evaluation (IFE). Matriks EFE digunakan untuk mengetahui peluang terbesar dan terkecil yang dimiliki perusahaan dan ancaman terbesar maupun ancaman yang tidak mempengaruhi perusahaan. Sedangkan, matriks IFE untuk mengetahui kekuatan terbesar dan terkecil yang dimiliki maupun kelemahan terbesar dan terkecil yang dimiliki perusahaan. Cara menghitungnya adalah dengan mengalikan bobot dengan rating. Bobot didapatkan dari nilai 1 (kurang penting) sampai 3 (lebih penting) dengan menggunakan Paired
Comparison Scales. Nilai rating adalah skala 1 sangat lemah sampai skala 4 sangat kuat.

\subsection{Alat Analisis Data}

Tahap berikutnya adalah tahap analisis. Model yang dapat digunakan sebagai alat analisis adalah matriks SWOT (Strengths, Weaknesses, Opportunities, Threats). Matriks SWOT digunakan untuk mengetahui dan menganalisis strategi mana yang akan diambil.

Tahap ketiga, yaitu pengambilan keputusan. Digunakan Quantitative Strategic Planning Matrix (QSPM) pada tahapan ini. Setelah berhasil mengembangkan sejumlah alternatif strategi, perusahaan harus mampu mengevaluasi dan kemudian memilih strategi yang terbaik. Strategi ini diharapkan sesuai dengan kondisi internal perusahaan serta lingkungan eksternal.

\section{HASIL PENELITIAN DAN PEMBAHASAN \\ 4.1. Gambaran Umum Strategi Pemasaran UKM Progress Jogja}

Strategi pemasaran yang saat ini dijalankan oleh UKM Progress Jogja adalah pemasaran aneka produk (product variety marketing). Disini UKM memproduksi wedang uwuh dalam berbagai variasi bentuk minuman dan variasi produk minuman herbal. Dengan demikian, UKM menyajikan berbagai produk kepada pembeli dan bukan pada berdasarkan segmennya.

Target atau fokus produksi adalah pada produk minuman tradisional (khususnya wedang uwuh) dan tepung bebas gluten. Produk minuman tradisional khususnya wedang uwuh dengan segala variannya, sehingga memberikan kemudahan konsumen dalam menikmatinya memiliki permintaan yang cenderung lebih sering atau permintaan tinggi. Sedangkan pada produk tepung bebas gluten, permintaan cukup besar juga bahkan sampai menjangkau luar negeri. UKM Progress Jogja membangun posisinya sebagai produsen produk berbasis bahan baku lokal menjadi pangan sehat dari bahan alami yang siap dikonsumsi dan cara pembuatannya sederhana. 
Produk jadi sampai kepada pelanggan melalui berbagai macam saluran distribusi. Untuk produk yang akan disampaikan kepada pelanggan luar negeri ada yang menggunakan saluran distribusi mulai dari eksportir, distributor besar, distributor kecil / retailer / agen. Akan tetapi, dapat pula penjualan dilakukan secara langsung kepada pelanggan atau melalui media online.

Berbeda halnya untuk pelanggan dalam negeri. Penjualan dilakukan melalui empat cara, yaitu langsung, baik melalui outlet yang sekaligus tempat produksi, maupun melalui media online yang dikelola oleh pemilik UKM Progress Jogja (e-commerce), kemudian adapula yang menggunakan saluran distribusi dari distributor (besar) distributor kecil (retailer / agen) sampai ke pelanggan atau langsung dapat pula melalui retailer/agen baru ke pelanggan. Proses penjualan juga menggunakan media online yang banyak ditawarkan oleh pihak luar atau dengan kata lain menggunakan e-commerce via perantara (Helia dan Handayani, 2015).

UKM Progress Jogja memiliki konsumen dari lokal, dalam dan luar negeri. Daerah yang menjadi pasar lokal adalah provinsi Daerah Istimewa Yogyakarta, kemudian untuk pasar dalam negeri meliputi provinsi Jawa Tengah, Jawa Barat, beberapa daerah di Jawa dan luar Jawa. Kemudian, untuk konsumen dari luar negeri adalah dari negara Jepang, Cina, Australia, dan lain sebagainya.

Walaupun sudah memiliki banyak konsumen, penyebaran produk masih belum terdistribusi secara luas dan merata, khususnya di Yogyakarta, sehingga masih diperlukan adanya strategi - strategi pemasaran yang efektif.

\subsection{Identifikasi Faktor - faktor Strategis Internal dan Eksternal}

Rangkuman dari identifikasi faktor faktor strategis internal dan eksternal terdapat pada tabel 1 .

\subsection{Rumusan Strategi Pengembangan Usaha}

\subsubsection{Analisis IFE}

Matriks IFE memberikan rumusan analisis lingkungan secara internal, meliputi evaluasi untuk kekuatan dan kelemahan pada suatu UKM dan juga memberikan dasar evaluasi hubungan antar bidang - bidang fungsional tersebut dapat dilihat pada tabel 2.

\subsubsection{Analisis Lingkungan Eksternal EFE}

Matriks EFE digunakan untuk merangkum peluang dan ancaman. Perhitungan matriks dilakukan terhadap bobot dan pemberian rating pada setiap faktor. Berikut ini dapat dilihat matriks EFE pada UKM Progress Jogja. Peluang yang paling tinggi adalah keberpihakan instansi pemerintah daerah pada pengembangan UKM dengan nilai 0,482 . Berikutnya adalah Tren back to nature (kembali ke gaya hidup sehat), perkembangan teknologi, pasar tersedia (dalam dan luar negeri), dan tersedianya tenaga kerja. 
Tabel 1. Identifikasi Faktor - faktor Internal UKM Progress Jogja

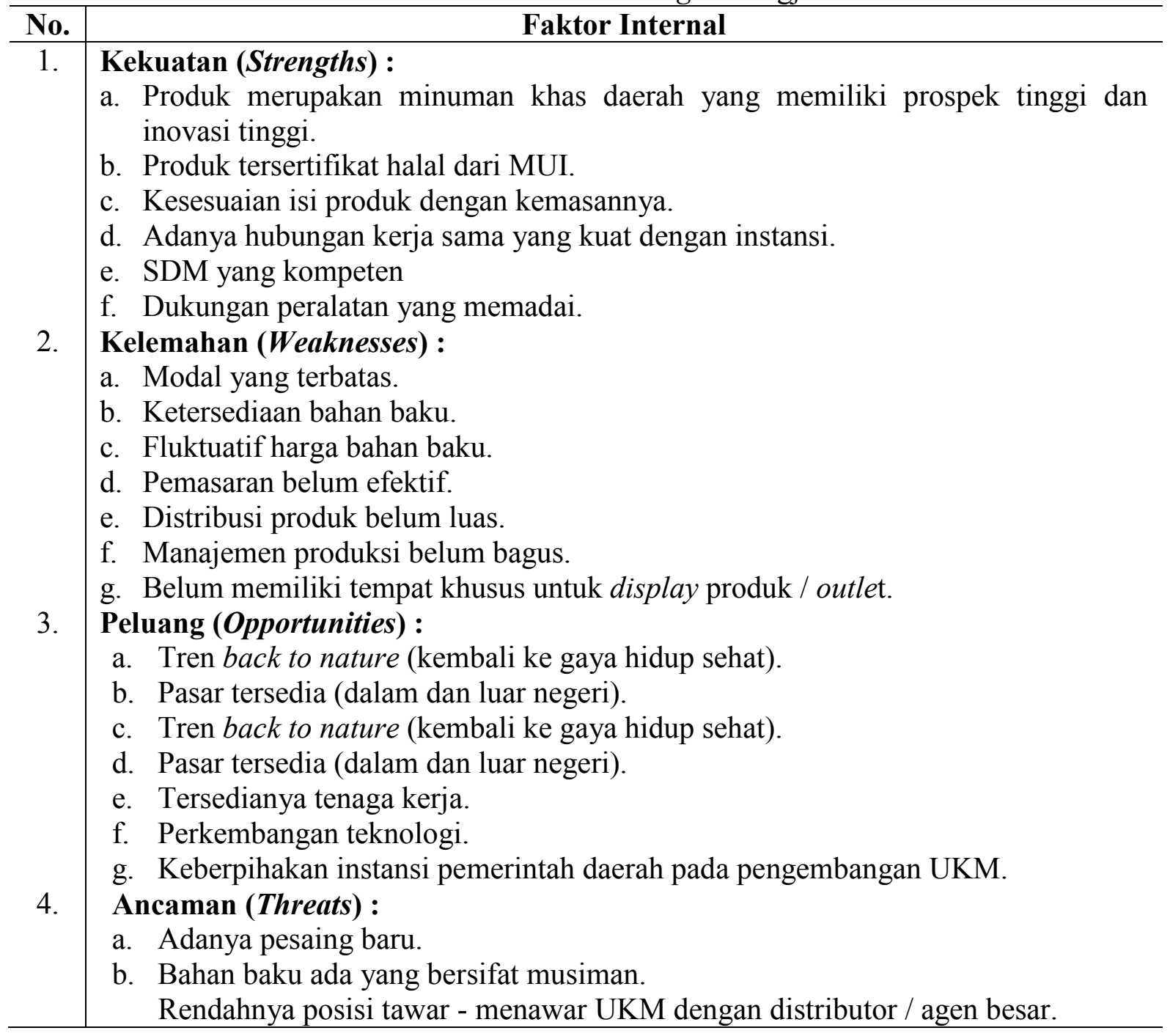

Sedangkan yang menjadi ancamannya adalah rendahnya posisi tawar menawar UKM dengan distributor / agen besar dengan nilai 0,429 . Kemudian, adanya pesaing baru $(0,393)$ dan bahan baku ada yang bersifat musiman $(0,25)$

Pada matriks IE UKM Progress Jogja pada gambar berikut terlihat bahwa UKM
Progress Jogja berada pada sel V, artinya bahwa UKM Progress Jogja berada pada strategi pertahankan dan pelihara, maka penetrasi pasar dan pengembangan produk merupakan dua strategi yang paling banyak dilakukan apabila perusahaan berada dalam sel ini. 
Tabel 2. Matriks IE UKM Progress Jogja

\begin{tabular}{|c|c|c|c|c|}
\hline \multirow{2}{*}{ No. } & Faktor Internal & Bobot & Rating & Skor \\
\hline & \multicolumn{4}{|l|}{ Kekuatan } \\
\hline A1 & $\begin{array}{l}\text { Produk merupakan minuman khas daerah yang } \\
\text { memiliki prospek tinggi dan inovasi tinggi. }\end{array}$ & 0,106 & 4 & 0,423 \\
\hline A2 & Produk tersertifikat halal dari MUI. & 0,061 & 4 & 0,244 \\
\hline A3 & Kesesuaian isi produk dengan kemasannya. & 0,077 & 4 & 0,308 \\
\hline A4 & $\begin{array}{l}\text { Adanya hubungan kerja sama yang kuat dengan } \\
\text { instansi. }\end{array}$ & 0,064 & 3 & 0,192 \\
\hline A5 & SDM yang kompeten. & 0,048 & 2 & 0,096 \\
\hline A6 & Dukungan peralatan yang memadai. & 0,074 & 2 & 0,147 \\
\hline
\end{tabular}

\section{Kelemahan}

\begin{tabular}{|c|c|c|c|c|}
\hline B1 & Modal yang terbatas. & 0,090 & 2 & 0,179 \\
\hline B2 & Ketersediaan bahan baku. & 0,080 & 2 & 0,160 \\
\hline B3 & Fluktuatif harga bahan baku. & 0,087 & 2 & 0,173 \\
\hline B4 & Pemasaran belum efektif. & 0,074 & 2 & 0,147 \\
\hline B5 & Distribusi produk belum luas. & 0,080 & 2 & 0,160 \\
\hline \multirow{2}{*}{$\begin{array}{l}\text { B6 } \\
\text { B7 }\end{array}$} & Manajemen produksi belum bagus. & 0,080 & 3 & 0,240 \\
\hline & $\begin{array}{l}\text { Belum memiliki tempat khusus untuk display produk } \\
\text { / outlet. }\end{array}$ & 0,080 & 3 & 0,240 \\
\hline \multicolumn{2}{|r|}{ TOTAL } & 1,000 & & 2,712 \\
\hline \multirow{2}{*}{ No. } & Faktor Eksternal & Bobot & Rating & Skor \\
\hline & \multicolumn{4}{|l|}{ Peluang } \\
\hline $\mathrm{C} 1$ & Tren back to nature (kembali ke gaya hidup sehat). & 0,107 & 4 & 0,429 \\
\hline $\mathrm{C} 2$ & $\begin{array}{l}\text { Pasar tersedia (dalam dan luar negeri/khususnya } \\
\text { negara MEA). }\end{array}$ & 0,143 & 2 & 0,286 \\
\hline $\mathrm{C} 3$ & Tersedianya tenaga kerja. & 0,143 & 2 & 0,286 \\
\hline $\mathrm{C} 4$ & Perkembangan teknologi. & 0,116 & 3 & 0,348 \\
\hline $\mathrm{C} 5$ & Dukungan instansi dan pemerintah daerah. & 0,161 & 3 & 0,482 \\
\hline
\end{tabular}

Ancaman

\begin{tabular}{c|l|c|c|c}
\hline D1 & Adanya pesaing baru & 0,098 & 4 & 0,393 \\
D2 & Bahan baku ada yang bersifat musiman & 0,125 & 2 & 0,250 \\
D3 & Tingkat persaingan usaha yang semakin tinggi & 0,107 & 4 & 0,429 \\
\hline \multicolumn{2}{c|}{ TOTAL } & 1,000 & & 2,902 \\
\hline
\end{tabular}




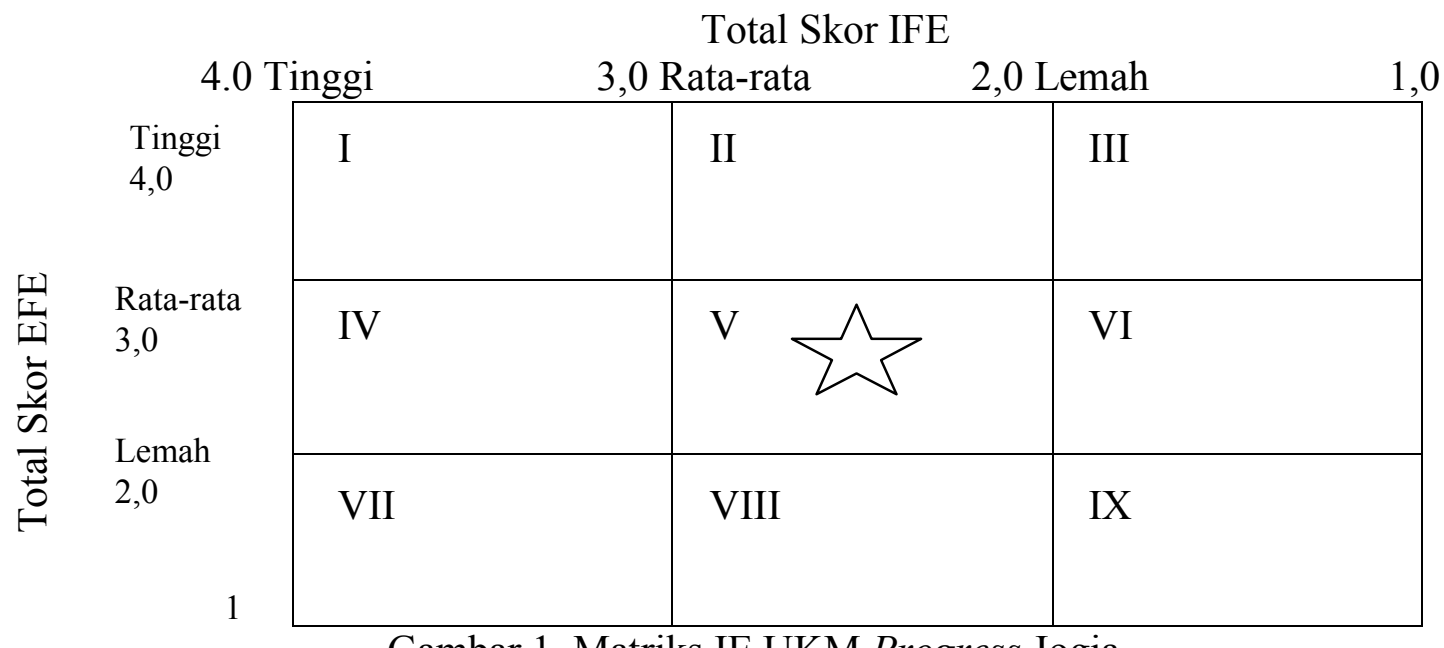

Gambar 1. Matriks IE UKM Progress Jogja.

Tabel 3. Matriks SWOT UKM Progress Jogja

\begin{tabular}{|c|c|c|}
\hline & $\begin{array}{l}\text { Kekuatan (Strength) : } \\
\text { a. Produk merupakan } \\
\text { minuman khas daerah } \\
\text { yang memiliki prospek } \\
\text { tinggi dan inovasi tinggi. } \\
\text { b. Produk tersertifikat halal } \\
\text { dari MUI. } \\
\text { c. Kesesuaian isi produk } \\
\text { dengan kemasannya. } \\
\text { d. Adanya hubungan kerja } \\
\text { sama yang kuat dengan } \\
\text { instansi. } \\
\text { e. SDM yang kompeten } \\
\text { f. Dukungan peralatan yang } \\
\text { memadai. }\end{array}$ & $\begin{array}{l}\text { Kelemahan (Weaknesses) : } \\
\text { a. Modal yang terbatas. } \\
\text { b. Fluktuatif harga bahan } \\
\text { baku. } \\
\text { c. Ketersediaan bahan baku. } \\
\text { d. Pemasaran belum efektif. } \\
\text { e. Distribusi produk belum } \\
\text { luas. } \\
\text { f. Manajemen produksi } \\
\text { belum bagus. } \\
\text { g. Belum memiliki tempat } \\
\text { khusus untuk display } \\
\text { produk / outlet. }\end{array}$ \\
\hline $\begin{array}{l}\text { Peluang (opportunities) } \\
\text { a. Tren back to nature } \\
\text { (kembali ke gaya hidup } \\
\text { sehat). } \\
\text { b. Pasar tersedia (dalam dan } \\
\text { luar negeri). } \\
\text { c. Tersedianya tenaga kerja. } \\
\text { d. Perkembangan teknologi. } \\
\text { e. Keberpihakan instansi } \\
\text { pemerintah daerah pada } \\
\text { pengembangan UKM. }\end{array}$ & $\begin{array}{l}\text { Strategi S-O } \\
\text { 1. Memperluas pangsa } \\
\text { pasar. } \\
\text { 2. Pengembangan variasi } \\
\text { produk. } \\
\text { 3. Menjaga kualitas dan } \\
\text { kehalalan produk. }\end{array}$ & $\begin{array}{l}\text { Strategi W-O } \\
\text { 1. Memperbaiki sistem } \\
\text { manajemen. } \\
\text { 2. Memperkuat modal } \\
\text { melalui bekerjasama } \\
\text { dengan instansi } \\
\text { pemerintahan. } \\
\text { 3. Mengembangkan } \\
\text { pemasaran melalui offline } \\
\text { dan online. }\end{array}$ \\
\hline $\begin{array}{l}\text { Ancaman (Threats): } \\
\text { a. Adanya pesaing baru. } \\
\text { b. Bahan baku ada yang } \\
\text { bersifat musiman. } \\
\text { c. Rendahnya posisi tawar } \\
\text { menawar UKM dengan } \\
\text { distributor / agen besar. }\end{array}$ & $\begin{array}{l}\text { Strategi } \mathbf{S}-\mathbf{T} \\
\text { 1. Menetapkan strategi harga } \\
\text { pasar untuk menghadapi } \\
\text { persaingan. } \\
\text { 2. Meningkatkan promosi. }\end{array}$ & $\begin{array}{l}\text { Strategi } \mathbf{W}-\mathbf{T} \\
\text { 1. Meningkatkan teknologi } \\
\text { 2. Penambahan outlet dan } \\
\text { jumlah distributor. }\end{array}$ \\
\hline
\end{tabular}




\subsubsection{Analisis Matriks SWOT dan QSPM}

Matriks SWOT merupakan langkah langkah kongkrit yang sebaiknya dilakukan oleh UKM Progress Jogja berdasarkan pengembangan dari matrik IE. Berbagai alternatif strategi dapat dirumuskan berdasarkan model analisis matriks SWOT. Strategi utama yang dapat disarankan terdapat empat macam, yaitu : strategi $\mathrm{SO}$, ST, WO, dan WT.

Analisis ini menggunakan data yang telah diperoleh dari matriks EFE dan IFE di atas. Hasil analisis dapat dilihat pada keunggulan dari penggunaan model ini adalah mudah memformulasikan strategi berdasarkan gabungan faktor eksternal dan internal.

Dari penyusunan strategi pada matriks SWOT dihasilkan beberapa alternatif strategi antara lain :

1. Memperluas Pangsa Pasar.

2. Pengembangan Variasi Produk.

3. Menjaga Kualitas dan Kehalalan Produk.

4. Memperbaiki Sistem Manajemen.

5. Memperkuat Modal Melalui Bekerjasama dengan Instansi

Pemerintahan.

6. Mengembangkan Pemasaran Melalui Offline dan Online.

7. Menetapkan Strategi Harga Pasar untuk Menghadapi Persaingan.

8. Meningkatkan Promosi.

9. Meningkatkan Teknologi.

10. Penambahan Jumlah Outlet dan Distributor.

Strategi yang tepat digunakan oleh UKM Progress Jogja berada pada strategi SO (Strengths - Opportunities) yang artinya dengan kekuatan dan peluang yang ada sehingga dapat memanfaatkan peluang yang ada. Strategi yang dipilih adalah memperluas pangsa pasar (khususnya dengan memanfaatkan keberpihakan pemerintah), pengembangan variasi produk, dan menjaga kualitas dan kehalalan produk. Untuk mendapatkan prioritas strategi yang dipilih adalah dengan menggunakan matriks QSPM.

Strategi yang memiliki Total Attractiveness Score paling tinggi adalah strategi pertama pada pilihan strategi S-O, yaitu memperluas pangsa pasar dengan nilai 7,20. Strategi inilah yang kemudian perlu diterapkan oleh UKM Progress Jogja dalam mengembangkan usahanya sehingga mampu mencapai pangsa pasar dalam dan luar negeri secara lebih luas.

Dalam konteks pemasaran halal terdapat tiga segmen konsumen berdasarkan kecenderungan mereka terhadap produk syariah, antara lain Syariah Loyalist, Floating Mass dan Conventional Loyalist (Karim \& Affif, 2005). Perluasan pangsa pasar yang dilakukan oleh UKM Progress Jogja sebaiknya mempertimbangkan segmen pasar Syariah Loyalist dan Floating Mass karena mereka akan memilih menggunakan produk yang tersertifikasi halal selain juga ditentukan oleh aspek fungsional seperti harga, ketersediaan dan kualitas dari produk tersebut.

\section{KESIMPULAN}

Strategi pemasaran halal yang dapat dipilih oleh UKM Progress Jogja sebagai prioritas utama adalah memperluas pangsa pasar (khususnya dengan memanfaatkan keberpihakan pemerintah), pengembangan variasi produk, dan menjaga kualitas dan kehalalan produk. Kemudian, dengan menggunakan matriks QSP maka prioritas strategi yang dipilih adalah memperluas pangsa pasar.

\section{Ucapan Terima Kasih}

Penelitian ini didukung oleh tim IbM Usaha Kecil Menengah Produk Wedang Uwuh dalam skema pendanaan Hibah Ristekdikti untuk pengabdian masyarakat tahun 2016. Penulis juga ingin mengucapkan terima kasih kepada seluruh staf dan manajemen dari UKM Progress Jogja yang telah mendukung terselesaikannya penelitian ini. 


\section{DAFTAR PUSTAKA}

David, F R. Manajemen Strategi : Konsepkonsep. Edisi Sembilan. Indeks, Jakarta, 2004.

Helia, V.N \& Handayani, D. Supply Chain Model Design for "Wedang Uwuh" SME in Daerah Istimewa Yogyakarta (Case Study on Progress Jogja SME). Proceeding $8^{\text {th }}$ International Seminar on Industrial Engineering and Management (ISIEM), 2015.

Islam, T., \& Chandrasekaran, U. Halal Marketing Growing The Pie. International Journal of Management Research (IJMRR),3,3938-3948, 2013.

Karim, A. dan Afif, Islamic Banking in Indonesia: a Qualitative Approach. 6th Conference On Islamic Economics and Finance. Jakarta, Indonesia, p.52, 2005.

Kotler, P. Manajemen Pemasaran, Analisis, Perencanan dan Pengendalian. Jilid 1, Jakarta, 1999.

Ningrum, P.A.H. Analisis Strategi Pemasaran Usaha Jasa Pembuatan dan Perbaikan Furniture UD. Suryani Furniture, Bogor, Jawa Barat. Skripsi tidak dipublikasikan. Bogor : Fakultas Ekonomi dan Manajemen, 2010.

Putra, E.P. Presentase Umat Islam di Indonesia jadi 85\%. Republika, Sabtu 9 Januari 2016.

Republika, Mendorong Daya Saing Koperasi dan UKM. Republika, 16 Agustus 2014.

Salehudin, I. dan Mukhlis, B.M., Pemasaran Halal: Konsep, Implikasi, dan Temuan di Lapangan, in Ikatan Alumni FEUI (Ed.), Dulu mendengar sekarang bicara: kumpulan tulisan ekonom muda FEUI, Lembaga Penerbit FEUI, Jakarta, 2012.

Suhaimi, E. UKM Harus Tingkatkan Daya Saing, diakses pada tanggal 10 Agustus 2016

dari

http://www.kemenperin.go.id/artikel/605 8/UKM-Harus-Tingkatkan-Daya-Saing, 2016.

Undang-Undang No.33 Tahun 2014 tentang Jaminan Produk Halal, 2014. 